\title{
Alginate Encapsulation as a Preservation Method of Pitaya Fruit Juice (Stenocereus spp.)
}

Juan Antonio Rodríguez-Sánchez ${ }^{1}$, María Isabel Cuatzo-Lozano², María Guadalupe Pérez-Loredo ${ }^{1}$, Diana Imelda Abarca-Sarro $^{1}$ and Yoja Gallardo Navarro ${ }^{2}$

1. Department of Environmental Systems Engineering, Escuela Nacional de Ciencias Biológicas, Instituto Politécnico Nacional. Wilfrido Massieu s/n Ave., Unidad Profesional Adolfo López Mateos, Mexico City 07738, Mexico

2. Department of Biochemical Engineering, Escuela Nacional de Ciencias Biológicas, Instituto Politécnico Nacional. Wilfrido Massieu s/n Ave., Unidad Profesional Adolfo López Mateos, Mexico City 07738, Mexico

\begin{abstract}
Alginate is a widely used polymer matrix in food industry since it allows formation of spherical, soft, and strong membranes adequate for encapsulation of a large amount of products, including food. The flow rate of alginate solutions and the permeability of the capsules were evaluated within an acidic-low acidic $\mathrm{pH}$ range and different alginate concentrations. In solutions adjusted at different $\mathrm{pH}$ (3.0 to 7.0) with concentrations of alginate of $0.8,1.0$, and $1.2 \% \mathrm{w} / \mathrm{v}$, flow rates at $20{ }^{\circ} \mathrm{C}$ were 6.95 to 10.00 , 4.54-5.35, and 2.60-2.80 $\mathrm{mL} \mathrm{s}^{-1}$, respectively. Permeability of the capsules was evaluated in terms of the diffusion of $\mathrm{H}^{+}$ions (expressed as $\mathrm{pH}$ ) and soluble solids ( ${ }^{\circ} \mathrm{Brix}$ ). Meanwhile both diffusions were minor at $4.0<\mathrm{pH}<7.0$ and were significantly superior at more acidic pH $(\mathrm{P}<0.05)$, alginate concentration did not present significant effect. Yellow, purple, and red juices from Stenocereus spp. fruits (pitayas) were encapsulated using $1.0 \%$ of alginate and stored with isotonic solution $\left(3 \mathrm{~mL} \mathrm{~g}^{-1}\right)$ at $4{ }^{\circ} \mathrm{C}$ in the dark. The capsules were spherical with diameter between 4.59 and $470 \mathrm{~mm}$, weight from 82.60 to $97.50 \mathrm{mg}$, and volume of $0.075-0.098 \mathrm{~mL}$. Pigment (total betalains content) diffusion reached equilibrium at $24 \mathrm{~h}$ of storage, at which point retentions of total betalains in the yellow, purple, and red capsules were $87.79,96.13$, and $85.13 \%$, respectively. Also, changes in the color of the capsules were observed during storage.
\end{abstract}

Key words: Stenocereus, pitaya, betalains, alginate encapsulation, color stability.

\section{Introduction}

The Stenocereus genus (pitaya) is a plant native to America with some species endemic to Mexico [1]. The fruits from pitaya may have yellow, red or purple pulp [2], whose color is due to the presence and concentration of betalains, water-soluble pigments with antioxidant properties and positive effects on human health [3]. According to their chemical structure, betalains are divided into two groups: yellowish betaxanthins, and reddish betacyanins [4].

The production of pitaya in Mexico has increased more than $200 \%$ in the last 10 years [5]. The fruits are locally consumed fresh and their juices have great sensorial acceptance due to their pulp color and high

Corresponding author: Gallardo-Navarro, T. Y., professor, research field: food technology. acidity, which confers a pleasant sweet-sour taste [2]. Nevertheless, the fruit shelf-life is no longer than 6 days [6] and new methods of preservation of pitaya fruit, pulp or juice are required in order to extend product shelf-life, for instance encapsulation [7].

Encapsulation is a technology of packaging solid or liquid materials, which are covered with semipermeable, spherical, and strong membranes [8] that provide enhanced stability under unfavorable environmental conditions [9]. This technology can be used for many applications in food industry: to stabilize the core material, control the oxidative reaction, provide controlled or sustained release, mask flavors, colors or odors, extend shelf life or preserve active compounds against loss, such as fatty acids [10], pigments [11], phenolic compounds [12], and 
microorganisms [13] among others.

The use of natural polymers in techniques of food encapsulation is advantageous over the use of synthetic ones due to their biocompatibility. Equally important is that natural polysaccharides are available in their raw form from natural sources. Furthermore, they are biodegradable, inexpensive, and friendly with the environment [14]. Several matrixes, such as maltodextrin, starch, gelatin, whey protein, caseinate, Arabic gum, chitosan, or alginate [15] are mainly used, applying different encapsulation technologies. Alginate encapsulation is an ionic gelation method and is one of the most widely used in food conservation due to its biocompatibility and low toxicity [16]; it also allows preserving ready-to-eat food for long storage periods in adequate conditions [17].

Alginic acid is extracted from seaweeds and is composed of units of mannuronic (M) and guloronic (G) acids in different proportions, depending on the source and growth conditions. These units are present in block copolymers (MM, GG, and MG). The binding of divalent cations and subsequent gel formation depend on the arrangement and relation of the blocks [18]. The GG blocks exhibit preferential binding sites for divalent counter-ions (for instance $\mathrm{Ca}^{2+}, \mathrm{Ba}^{2+}, \mathrm{Fe}^{2+}$, or $\mathrm{Sr}^{2+}$ ), and the bound ions interact with other blocks to form links that subsequently form gel structures; on the other hand, MM and MG blocks provide flexibility to the structure. Interfacial polymerization is instantaneous when sodium alginate solution is added to a calcium solution, with calcium alginate precipitation followed by a gradual gelation of the interior of the capsule as $\mathrm{Ca}^{2+}$ permeate trough the alginate system [17]. The characteristics of the gel can be manipulated by modifying manufacturing conditions: temperature, $\mathrm{pH}$, ion concentration or alginate concentration.

The flow rate of aqueous alginate solutions and permeability of alginate capsules were analyzed as a function of the alginate concentration and $\mathrm{pH}$ of the aqueous solution. In addition, encapsulation of pitaya juices was performed to evaluate its preservation during storage.

\section{Materials}

\subsection{Chemicals}

Food-grade sodium alginate, calcium carbonate, citric acid, sodium chloride, and sucrose (Mexico).

\subsection{Plant Material}

Yellow fruits (pitayas) from Stenocereus pruinosus, purple, and red pitayas from Stenocereus stellatus were collected from Santiago Tonahuiztla, Puebla, Mexico, during harvesting season in 2013.

\section{Methods}

\subsection{Alginate Solutions Encapsulation}

Sodium alginate was dissolved in water (adjusted at $\mathrm{pH} 3,3.5,4,5,6$, and 7 with citric acid) at 3 different concentrations $(0.8,1.0$, and $1.2 \% \mathrm{w} / \mathrm{v})$ at $60{ }^{\circ} \mathrm{C}$. Using a separation funnel, alginate solutions were dropped at $20{ }^{\circ} \mathrm{C}$ into a $1.0 \% \mathrm{w} / \mathrm{v}$ calcium chloride solution without agitation, where capsules were kept for one minute. After that, capsules were washed with water and then storaged in aqueous medium. Flow rate of alginate solutions and permeability of alginate capsules were measured.

\subsection{Flow Rate of Alginate Solutions}

Flow rate was determined using samples of alginate solutions at different concentrations and $\mathrm{pH} ; 100 \mathrm{~mL}$ samples were placed into a separation funnel opened to a quarter of the total aperture and total flow time was measured at $20^{\circ} \mathrm{C}$. The results were expressed as $\mathrm{mL}$ of solution per second ( $\mathrm{mL} \mathrm{s}-1)$.

\subsection{Permeability of Alginate Capsules}

Capsules were elaborated according to 3.1. section and then storaged with distilled water as packing liquid with a solution/capsule ratio of $2 \mathrm{~mL}$-1 during $0,1,2,3,4,5,6,7,10,17,21$, and $24 \mathrm{~d}$ at $4{ }^{\circ} \mathrm{C}$ in the 
dark.

Capsules were drained and packing liquid was measured to $\mathrm{H}^{+}$, expressed as $\mathrm{pH}$ (Denver Instrument, UB-10, USA) and total soluble solids (Boeco, VBR32, Germany), expressed as ${ }^{\circ}$ Brix.

\subsection{Fruit Selection and Juice Preparation}

Undamaged yellow, purple, and red pitayas without spines were packed in Food Saver ${ }^{\circledR}$ plastic bags of $500 \mathrm{~g}$ to $800 \mathrm{~g}$ whole fruit under vacuum, and stored at $-20{ }^{\circ} \mathrm{C}$ until encapsulation. Prior to encapsulation, samples were placed at $20{ }^{\circ} \mathrm{C}$ for 1 day, and peel. Using a juice extractor (Nutri-Max, Mexico), seeds were removed from the pulp, which was sieved through $710 \mu \mathrm{m}$ mesh, and then centrifuged (Velocity 14R, Dynamica Scientific, UK) at $10,576 \times \mathrm{g}$ for 20 $\min$ at $20{ }^{\circ} \mathrm{C}$. Juices were analyzed for $\mathrm{pH}$, total betalains, and color parameters.

\subsection{Alginate Encapsulation of Pitaya Fruit Juices}

Sodium alginate was mixed with pitaya juice $(1.0 \%$ $\mathrm{w} / \mathrm{v})$ until homogenization at $60{ }^{\circ} \mathrm{C}$. Using a separation funnel, homogenized pulp with sodium alginate was dropped at $20{ }^{\circ} \mathrm{C}$ into a $1.0 \% \mathrm{w} / \mathrm{v}$ calcium chloride solution without agitation, where capsules were kept for one minute. After that, capsules were washed with water and then storage with isotonic solution ( $0.1 \mathrm{M}$ sodium chloride, $0.3 \mathrm{M}$ sucrose) as packing liquid with a solution/capsule ratio of $3 \mathrm{~mL}$ g-1 during $0,1,2,4,6,24,48,72,96$, and $120 \mathrm{~h}$ at $4{ }^{\circ} \mathrm{C}$ in the dark.

For analysis, capsules were drained and their color was determined, the packing liquid was used to measure betalain content.

\subsection{Quantification of Betalains}

Total betalains (the sum of betacyanin and betaxanthin) content were quantified using a UV-Vis spectrophotometer [19]. Pigment concentrations were calculated using Eq. (1).

$$
B=\frac{(A \times D F \times W)}{(\varepsilon \times \mathrm{L})} \times 1,000
$$

Where B is betaxanthin and betacyanin content ( $\mu \mathrm{g}$ $\mathrm{mL}-1$ or $\mu \mathrm{g}$ g-1) using indicaxanthin and betanin respectively as reference. A is absorbance ( $483 \mathrm{~nm}$ for betaxanthin and $538 \mathrm{~nm}$ for betacyanin), DF is dilution factor, $\mathrm{W}$ is molecular weight: $550 \mathrm{~g}$ mol-1 for betanin, and $308 \mathrm{~g}$ mol-1 for indicaxanthin); $\varepsilon$ represents the molar extinction coefficient $(60,000 \mathrm{~L}$ mol-1 cm-1 for betanin and 48,000 for indicaxanthin), and $\mathrm{L}$ is path length $(1 \mathrm{~cm})$.

A mass balance was performed to determinate betalain retention in capsules. At each time, betalain content in capsules was calculated by the difference between initial content in capsules and pigment content in the isotonic solution.

\subsection{Color}

Chromatic parameters $\left(\mathrm{L}^{*}, \mathrm{a}^{*}\right.$, and $\left.\mathrm{b}^{*}\right)$ were measured at $0,24,48,92,96$, and $120 \mathrm{~h}$ using a colorimeter (Hunter Lab, Color Flex EZ, USA). Samples of drained capsules were placed in a quartz cell with a measurement area of $5 \mathrm{~cm}(2$ in) in diameter. The illuminant used was D65, and the standard observer angle was $10^{\circ}$ against a white background. With $\mathrm{a}^{*}$ and $\mathrm{b}^{*}$ values, Hue angle $\left(\mathrm{H}^{\circ}\right)$ and Chroma $\left(\mathrm{C}^{*}\right)$ were calculated using Eqs. (2) and (3), respectively.

$$
\begin{gathered}
H^{\circ}=\tan ^{-1}\left(\frac{b^{*}}{a^{*}}\right) \\
C^{*}=\sqrt{\left(a^{*}\right)^{2}+\left(b^{*}\right)^{2}}
\end{gathered}
$$

\subsection{Statistical Analysis}

Results are reported as mean \pm standard deviations $(\mathrm{n}=3)$. Means were compared by analysis of variance and Tukey's comparison test $(\mathrm{P}<0.05)$. Data were analyzed using Minitab 16 (Minitab Inc., USA).

\section{Results and Discussion}

\subsection{Flow Rate of Alginate Solutions}

The mechanical and physicochemical properties of alginate structures are affected by the composition and the formation process [20]. Regardless $\mathrm{pH}$ values, 
changes in the consistence and in the flow rate of solutions were observed with different alginate concentrations (Table 1): the higher alginate concentration in the solution, the greater viscosity or flow resistance [21].

Aqueous alginate solutions present shear-thinning behavior and are non-Newtonian fluids [16]. When the alginate is in solution it behaves as pseudoplastic and as Newtonian fluids at concentrations of $2.5 \%$ and $0.5 \%$, respectively [22], but there is not a well-defined characterization of the fluids at concentrations in between.

On the other hand, flow rate (or thickness) for the $0.8 \%$ alginate solution peaked at $\mathrm{pH}$ of 6 . Moreover, the maximum resistance to flow was reached at $\mathrm{pH} 3.5$ for solutions formulated with 1.0 and $1.2 \%$ of alginate. It has been reported that greater thickness of alginate solutions is reached at $3<\mathrm{pH}<4$ [23]; in contrast, some authors reported that the resistance to flow increases at pH 5 and it is unstable above 11 [22].

\subsection{Permeability of the Capsules}

The permeability and other properties of alginate gel structures (such as viscosity, strength, molecular weight, among others) are directly influenced by several process conditions, in particular alginate concentration, $\mathrm{pH}$, temperature, alginate composition, and availability of calcium ions [24, 21].

Regardless alginate concentration, with capsules of $\mathrm{pH}<3.5$ solutions diffusion of $\mathrm{H}^{+}$ions through membranes was increased $(\mathrm{P}<0.05)$ after $24 \mathrm{~d}$ of storage among different encapsulated solutions. Thus,
$\mathrm{pH}$ of liquid packing (water) was diminished over time. Indeed, $\mathrm{pH}$ decreased from 7.5 to $4.5,4.3$, and 4.1 after $24 \mathrm{~d}$ in liquid packing of capsules manufactured with solution at $\mathrm{pH}=3.0$ and 0.8 (Fig. 1A), 1.0 (Fig. 1B) and 1.2\% (Fig. 1C) of alginate, respectively. Solutions with less $\mathrm{H}^{+}$diffusion were those encapsulated at $4.0<\mathrm{pH}<7.0$ for all alginate concentrations assayed $(\mathrm{P}<0.05)$. Alginate films in aqueous medium are fully permeable due to their high porosity and large amount of water in the gel structure [14].

Similarly to diffusion of $\mathrm{H}^{+}$ions, acidic $\mathrm{pH}$ values $(<4.0)$ increased soluble solids diffusion from capsules to the medium and $4.0<\mathrm{pH}<7.0$ showed less ${ }^{\circ}$ Brix in liquid packing.

Therefore, low acidic $\mathrm{pH}$ grants superior capsule integrality over time. Indeed, in $0.8 \%$ alginate capsules the minimal diffusion of solids was observed with $\mathrm{pH}=6.0$; however, statistical differences were no significant $(\mathrm{P}<0.05)$ after $24 \mathrm{~d}$ of storage among $\mathrm{pH}$ range tested (Fig. 2A).

Furthermore, $\mathrm{pH} 4.0$ and 6.0 showed fewer soluble solids permeability than other $\mathrm{pH}$ values assayed $(\mathrm{P}<$ 0.05 ) for $1.0 \%$ alginate capsules (Fig. 2B). Moreover, in those manufactured with $1.2 \%$ of alginate, $\mathrm{pH}=7.0$ guaranteed physical stability of capsules over time, even though there were no significant statistical differences $(\mathrm{P}<0.05)$ among conditions evaluated (Fig. 2C).

\subsection{Alginate Encapsulation of Pitaya Juices}

Pitaya juice $(4.05<\mathrm{pH}<4.87)$ adequately formed

Table 1 Flow rates of solutions at several $\mathrm{pH}$ values (3-7) and different alginate concentrations $(0.8 \%, 1.0 \%$, and $1.2 \%)$.

\begin{tabular}{llll}
\hline & \multicolumn{3}{c}{ Flow rates of alginate solutions $\left(\mathrm{mL} \mathrm{s}^{-1}\right)$} \\
\cline { 2 - 4 } $\mathrm{pH}$ & $0.8 \%$ & $1.0 \%$ & $1.2 \%$ \\
\hline 3 & $6.95 \pm 0.08^{\mathrm{d}}$ & $4.54 \pm 0.40^{\mathrm{b}}$ & $2.68 \pm 0.03^{\mathrm{b}}$ \\
3.5 & $9.01 \pm 0.28^{\mathrm{bc}}$ & $5.35 \pm 0.08^{\mathrm{a}}$ & $2.80 \pm 0.02^{\mathrm{a}}$ \\
4 & $9.01 \pm 0.16^{\mathrm{bc}}$ & $5.29 \pm 0.13^{\mathrm{a}}$ & $2.79 \pm 0.04^{\mathrm{a}}$ \\
5 & $8.77 \pm 0.10^{\mathrm{c}}$ & $4.76 \pm 0.08^{\mathrm{b}}$ & $2.67 \pm 0.05^{\mathrm{b}}$ \\
6 & $10.00 \pm 0.11^{\mathrm{a}}$ & $5.00 \pm 0.06^{\mathrm{ab}}$ & $2.70 \pm 0.02^{\mathrm{b}}$ \\
7 & $9.29 \pm 0.10^{\mathrm{b}}$ & $4.59 \pm 0.06^{\mathrm{b}}$ & $2.79 \pm 0.02^{\mathrm{a}}$ \\
\hline
\end{tabular}

Different letters represent significant differences between $\mathrm{pH}$ values $(\mathrm{P}<0.05)$. 

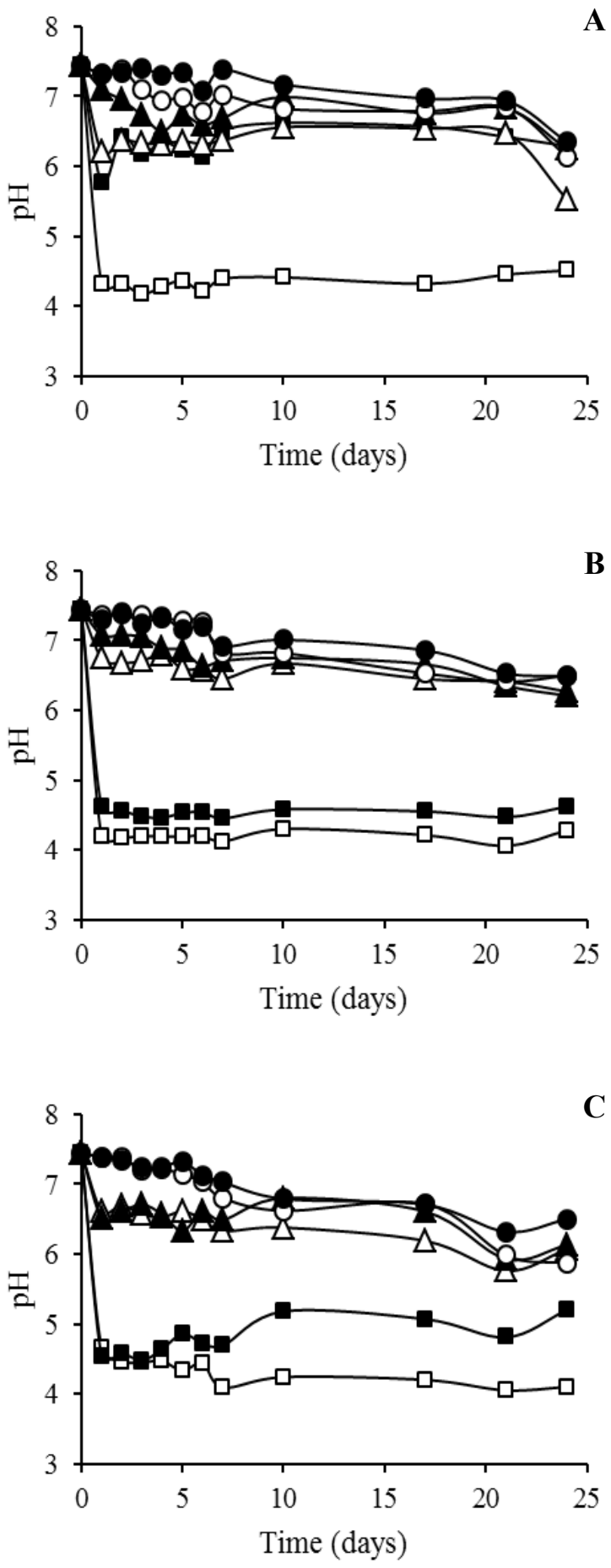

Fig. 1 Diffusion of $\mathrm{H}^{+}$ions from capsules to medium expressed as pH. Capsules were prior adjusted at pH $3(\square)$, $3.5(\square), 4(\Delta), 5(\Delta), 6(\circ)$, and $7(\bullet)$. Capsules were manufactured with $0.8 \%(\mathrm{~A}), 1.0 \%$ (B), $1.2 \%$ (C) of alginate.
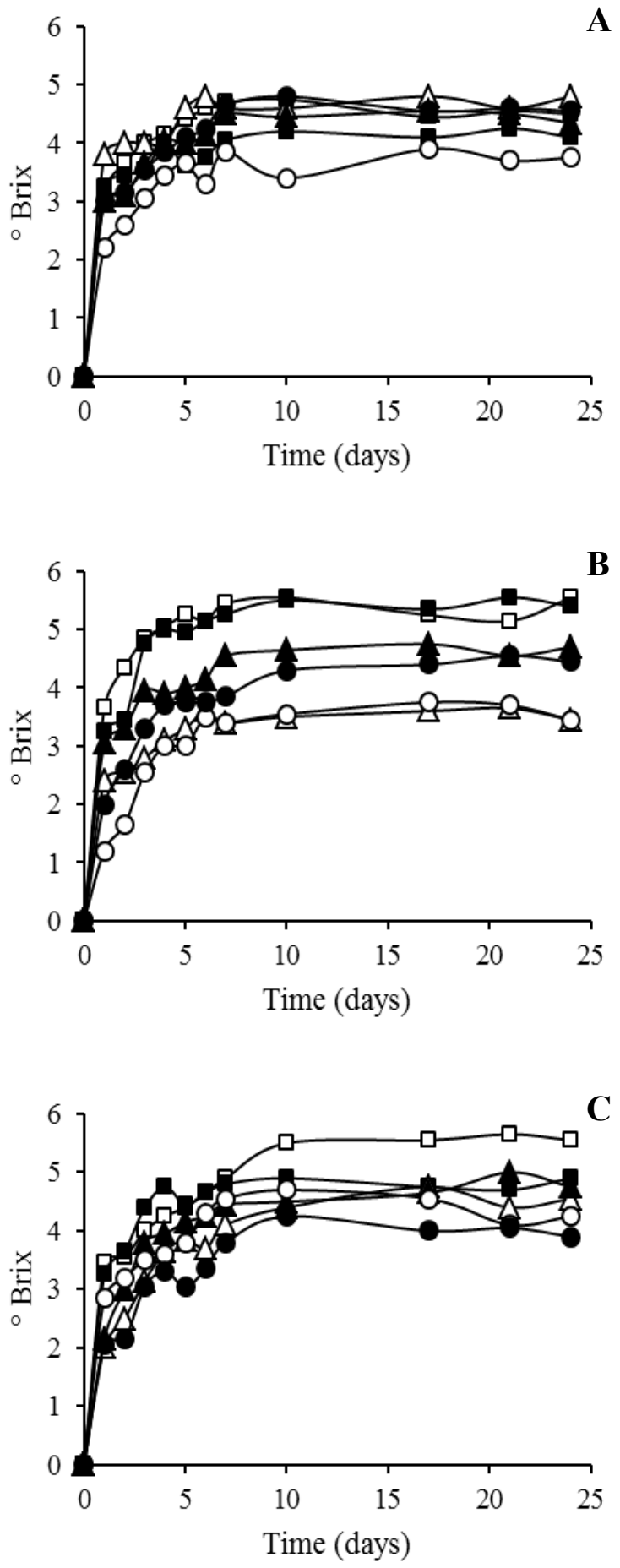

Fig. 2 Diffusion of soluble solids from capsules to medium expressed as ${ }^{\circ}$ Brix. Capsules were prior adjusted at $\mathbf{p H} 3$ $(\square), 3.5(\square), 4(\Delta), 5(\Delta), 6(\circ)$, and $7(\bullet)$. Capsules were manufactured with $0.8 \%(\mathrm{~A}), 1.0 \%(\mathrm{~B})$, and $1.2 \%$ (C) of alginate. 
capsules (Fig. 3) using 1.0\% of sodium alginate as polymer matrix. The capsules presented a spherical shape with similar diameter, weight, and volume among fruits (Table 2).

Equilibrium of pigment diffusion from the capsules to the media was reached within $24 \mathrm{~h}$ with retention of total betalains in the capsules of $87.79 \pm 0.06,96.13 \pm$ 0.05 , and $85.13 \pm 0.12 \%$ in the yellow, purple, and red juice, respectively; mentioned retentions were

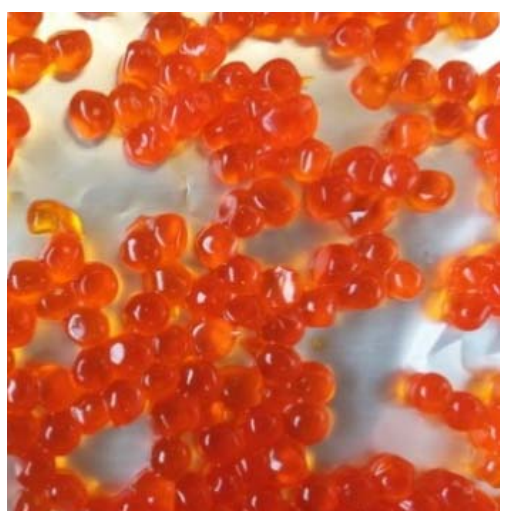

(a)

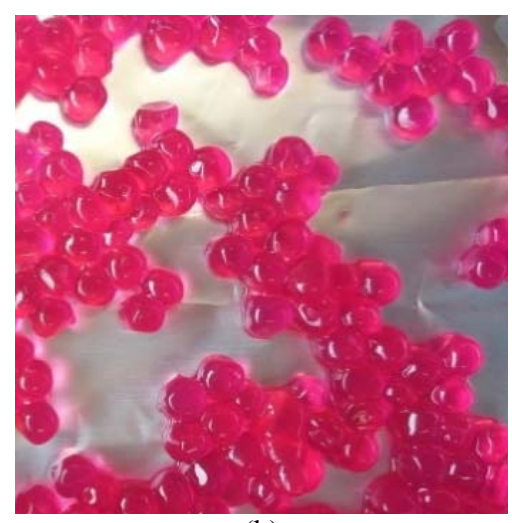

(b) maintained for $120 \mathrm{~h}$ without significant differences (Fig. 4).

Pigment diffusion affected the chromatic parameters of the capsules during storage (Table 3). Changes in $L^{*}$ values suggested that capsules presented brighter colors at the end of the experiment.

On the other hand, $\mathrm{H}^{\circ}$ indicated changes in the tone of the product along with more saturated colors $\left(\mathrm{C}^{*}\right.$ values) with storage.

Fig. 3 Alginate capsules of yellow (A), purple (B), and red (C) pitaya juice.

Table 2 Physical characterization of juice capsules.

\begin{tabular}{llll}
\hline Pitaya capsules & Diameter $(\mathrm{mm})$ & Weight $(\mathrm{mg})$ & Volume $(\mathrm{mL})$ \\
\hline Yellow & $4.61 \pm 0.19$ & $82.60 \pm 0.75$ & $0.075 \pm 0.01$ \\
Purple & $4.59 \pm 0.14$ & $83.10 \pm 7.56$ & $0.080 \pm 0.00$ \\
Red & $4.70 \pm 0.16$ & $97.50 \pm 0.35$ & $0.098 \pm 0.01$ \\
\hline
\end{tabular}

Presented results are the mean \pm S.D. of 3 replicates.

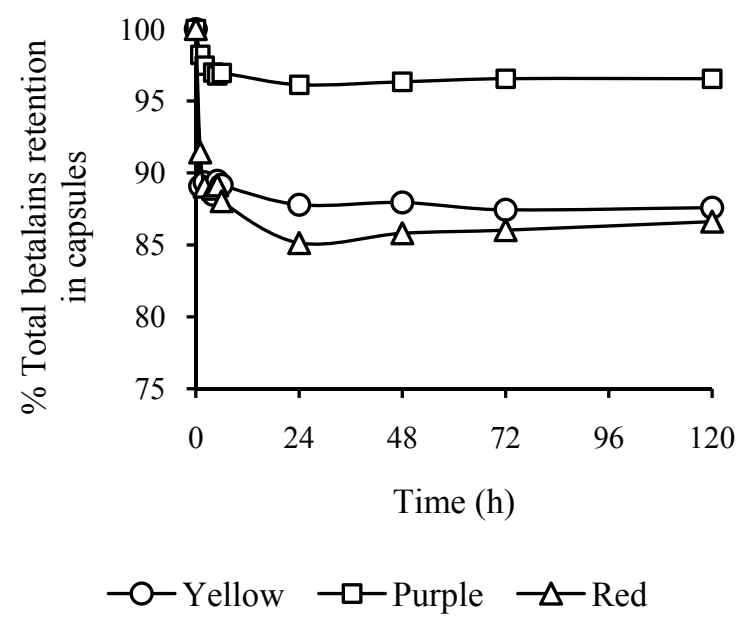

Fig. 4 Retention of total betalains in capsules of pitaya juices preserved using isotonic solution during $120 \mathrm{~h}$ of storage period at $4^{\circ} \mathrm{C}$. 
Table 3 Chromatic parameters of alginate capsules at 0,24 and $120 \mathrm{~h}$ of storage at $4{ }^{\circ} \mathrm{C}$.

\begin{tabular}{lllll}
\hline Capsules & Time $(\mathrm{h})$ & $\mathrm{L}^{*}$ & $\mathrm{H}^{\circ}$ & $\mathrm{C}^{*}$ \\
\hline \multirow{3}{*}{ Yellow } & 0 & $23.96 \pm 0.42$ & $37.52 \pm 0.17$ & $54.49 \pm 1.07$ \\
& 24 & $28.44 \pm 0.56$ & $45.42 \pm 0.37$ & $65.48 \pm 0.85$ \\
& 120 & $29.04 \pm 0.35$ & $45.17 \pm 1.46$ & $66.57 \pm 1.01$ \\
\hline \multirow{3}{*}{ Purple } & 0 & $22.05 \pm 0.09$ & $21.93 \pm 0.39$ & $49.98 \pm 0.42$ \\
& 24 & $25.39 \pm 0.44$ & $17.73 \pm 0.13$ & $54.83 \pm 0.35$ \\
& 120 & $25.82 \pm 0.84$ & $17.24 \pm 0.44$ & $56.20 \pm 1.65$ \\
\hline \multirow{3}{*}{ Red } & 0 & $17.89 \pm 0.03$ & $27.90 \pm 0.01$ & $45.82 \pm 0.08$ \\
& 24 & $20.22 \pm 0.82$ & $33.39 \pm 0.58$ & $58.24 \pm 1.45$ \\
\hline
\end{tabular}

Presented results are the mean \pm S.D. of 3 replicates.

In products pigmented with betalains, similar color changes have been reported $[25,26]$ during storage or stability tests, and they are directly related with the pigment stability, which is influenced by its concentration, temperature, presence of light, water activity, among others [4], conditions that should be controlled if a good color stability are desired.

\section{Conclusions}

In this paper it was demonstrated that alginate encapsulation is an adequate method to preserve food under controlled conditions.

Physical properties of the capsules are determined by the alginate concentration and $\mathrm{pH}$ used during process. Importantly, it was found that $\mathrm{pH}$ plays an important role in capsules stability during storage. Particularly, $\mathrm{pH}$ between 4.0 and 7.0 allows obtaining uniform and strong membranes with minimal diffusion of $\mathrm{H}^{+}$and soluble solids through the capsules.

Indeed, encapsulation of pitaya juices preserves betalain content in the capsules with good color stability during storage. Further sterilization after food encapsulation is recommendable in order to extend shelf life and to guarantee appropriate microbiological quality. This information may help to develop new products, and also increase commercialization and value of pitayas.

\section{Acknowledgements}

The present research was financially supported by
Consejo Nacional de Ciencia y Tecnología (CONACyT, Project CB-2011-01-169779). We would like to thank B. E. Barragán-Huerta for her support on color analysis, O.R. López-Mendiola for assistance with the gathering of fruits, and L.E. Ruíz-Molina for assistance in the identification of fruits species. We strongly recommend to the relevant authorities the consolidation of new projects of environmental and biodiversity conservation.

\section{References}

[1] Parra, F., Pérez-Nasser, N., Lira, R., Pérez-Salicrup, D., and Casas, A. 2008. "Population Genetics and Process of Domestication of Stenocereus Pruinosus (Cactceae) in the Tehuacán Valley, México." Journal of Arid Environments 72: 1997-2010.

[2] Pérez-Loredo, M. G., García-Ochoa, F., and Barragán-Huerta, B. E. 2015. "Comparative Analysis of Betalain Content in Stenocereus stellatus Fruits and Other Cactus Fruits Using Principal Component Analysis." International Journal of Food Properties 19: 326-38.

[3] García-Cruz, L., Valle-Guadarrama, S., Salinas-Moreno, Y., and Joaquín-Cruz, E. 2013. "Physical, Chemical, and Antioxidant Activity Characterization of Pitaya (Stenocereus pruinosus) Fruits." Plant Food for Human Nutrition 68: 403-10.

[4] Delgado-Vargas, F., Jimenez, A. R., and Paredes-Lopez, O. 2000. "Natural Pigments: Carotenoids, Anthocyanins and Betalains - Characteristics, Biosynthesis, Processing and Stability." Critical Reviews in Food Science and Nutrition 40: 173-289.

[5] Rodríguez-Sánchez, J. A., Cruz y Victoria, M. T., and Barragán-Huerta, B. E. 2017. "Betaxanthins and Antioxidant Capacity in Stenocereus pruinosus: Stability and Use in Food." Food Research International 91: 63-71. 
[6] García-Cruz, L., Valle-Guadarrama, S., Salinas-Moreno, Y., and Luna-Morales, C. C. 2016. "Postharvest Quality, Soluble Phenols, Betalains Content, and Antioxidant Activity of Stenocereus pruinosus and Stenocereus stellatus Fruit." Postharvest Biology and Technology 111: 69-76.

[7] Vergara, C., Saavedra, J., Sáenz, C., García, P., and Robert, P. 2014. "Microencapsulation of Pulp and ultrafiltered Cactus Pear (Opuntiaficus-indica) Extracts and Betanin Stability during Storage." Food Chemistry 157: 246-51.

[8] Anal, A. K., and Stevens, W. F. 2005. "Chitosan-Alginate Multilayer Beads for Controlled Release of Ampicillin." International Journal of Pharmaceutics 290: 713-24.

[9] Rodríguez-Amaya, D. B. 2016. "Natural Food Pigments and Colorants." Food Chemistry and Biochemistry 7: 20-6.

[10] Ghorbanzade, T., Jafari, S. M., Akhavan, S., and Hadavi, R. 2017. "Nano-encapsulation of Fish Oil in Nano-Liposomes and Its Application in Fortification of Yogurt." Food Chemistry 216: 146-52.

[11] Gandía-Herrero, F., Jiménez-Atiénzar, M., Cabanes, J., García-Carmona, F., and Escribano, J. 2010. "Stabilization of the Bioactive Pigment of Opuntia Fruits through Maltodextrin Encapsulation." Journal of Agricultural and Food Chemistry 58: 10646-52.

[12] Jia, Z., Dumont, M. J., and Orsat, V. 2016. "Encapsulation of Phenolic Compounds Present in Plants Using Protein Matrices." Food Bioscience 15: 87-104.

[13] Pimentel-González, D. J., Campos-Montiel, R. G., Lobato-Calleros, C., Pedroza-Islas, R., and Vernon-Carter, E. J. 2009. "Encapsulation of Lactobacillus rhamnosus in Double Emulsions Formulated with Sweet Whey as Emulsifier and Survival in Simulated Gastrointestinal Conditions." Food Research International 42: 292-7.

[14] Kilan, K., and Warszynski, P. 2014. "Thickness and Permeability of Multilayers Containing Alginate Cross-Linked by Calcium Ions." Electrochimical Acta 144: 254-62.

[15] Riaz, Q. U. A., and Masud, T. 2013. "Recent Trends and Applications of Encapsulating Materials for Probiotic Stability." Critical Reviews in Food Science and Nutrition 53: 231-44.
[16] Dávila, J. L., and d'Ávila, M. A. 2017. "Laponite as a Rheology Modifier of Alginate Solutions: Physical Gelation and Aging Evolution." Carbohydrate Polymers 157: 1-8.

[17] Anal, A. K., and Singh, H.2007. "Recent Advances in Microencapsulation of Probiotics for Industrial Applications and Targeted Delivery." Trends in Food Science and Technology 18: 240-51.

[18] Gemeiner, P., Rexová-Benková, L., Svec, F., and Norrlow, O. 1994. "Natural and Synthetic Carriers Suitable for Immobilization of Viable Cells, Active Organelles and Molecules." Edited by Veliky, I. A., and McLean, R. J. 67-84.

[19] Castellanos-Santiago, E., and Yahia, E. M. 2008. "Identification and Quantification of Betalains from the Fruits of 10 Mexican Prickly Pear Cultivars by High-Performance Liquid Chromatography and Electrospray Ionization Mass Spectrometry." Journal of Agricultural and Food Chemistry 56: 5758-64.

[20] Fabra, M. J., Talens, P., and Chiralt, A. 2010. "Influence of Calcium on Tensile, Optical and Water Vapour Permeability Properties of Sodium Caseinate Edible Films." Journal of Food Engineering 96 (3): 356-64.

[21] Comaposada, J., Gou, P., Marcos, B., and Arnau, J. 2015. "Physical Properties of Sodium Alginate Solutions and Edible Wet Calcium Alginate Coatings." LWT_Food Science and Technology 64: 212-9.

[22] Davidson, R., Cottrel, W., and Kovacs, P. 1980. "Handbook of Water-Soluble Gums and Resins." Editorial McGraw Hill, 260.

[23] Gliksman, M. 1969. "Gum Technology in the Food Industry.” Editorial Academic Press, 590.

[24] McHugh, D. J. 1987. "Production, Properties and Uses of Alginates.” In FAO Fisheries Technical Paper No. 288. Editorial Production and Utilization of Products from Commercial Seaweeds, 58-115.

[25] Güneser, O. 2016. "Pigment and Colour Stability of Beetroot Betalains in Cow Milk during Thermal Treatment." Food Chemistry 196: 220-7.

[26] Cai, Y., Sun, M., Schliemann, W., and Corke, H. 2001. "Chemical Stability and Colorant Properties of Betaxanthin Pigments from Celosia argentea." Journal of Agricultural and Food Chemistry 49: 4429-35. 